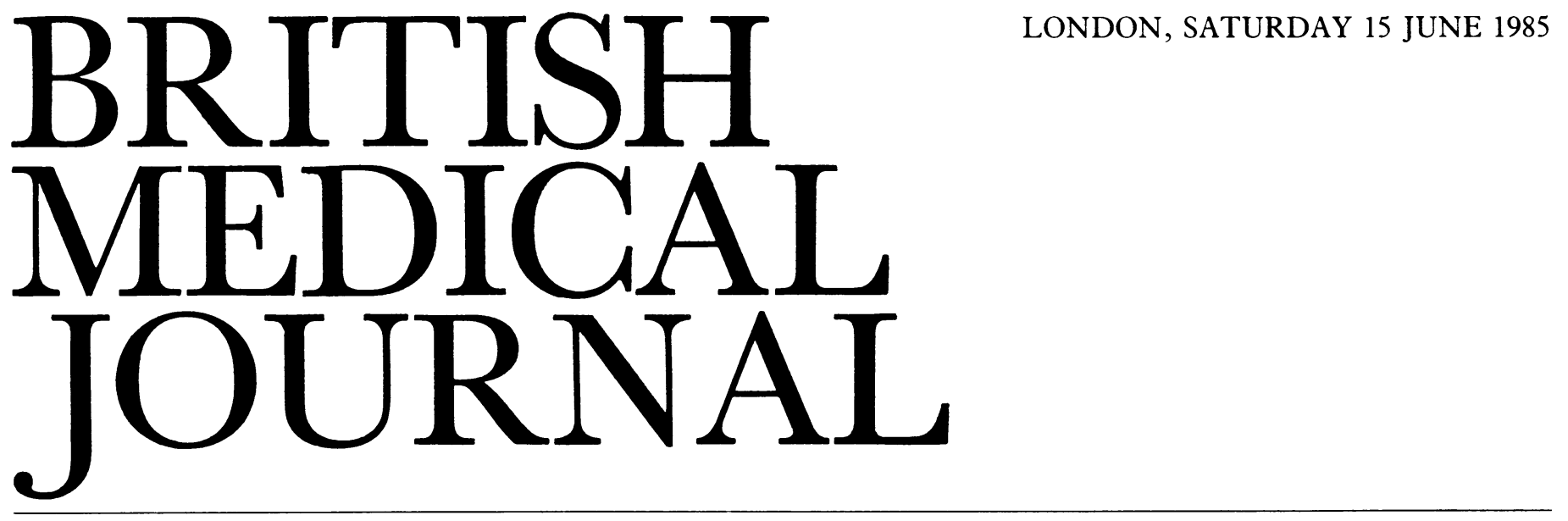

\title{
Smoking before surgery: the case for stopping
}

\begin{abstract}
A custom loathsome to the eye, harmful to the brain, dangerous to the lungs, and in the black stinking fume thereof, nearest resembling the horrible Stygian smoke of the pit that is bottomless.
\end{abstract}

To the adverse effects of smoking noted by King James in 1604 can now be added changes in the cardiovascular, immune, and haemostatic systems. Over 1000 components of cigarette smoke have been identified, ${ }^{1}$ and these may cause wide ranging disturbances of physiology. These compound the risks of anaesthesia and surgery though precise figures concerning the overall increase in operative morbidity and mortality are lacking.

The important question is: "For what period before operation must patients stop smoking in order to reduce this increase in operative risk?" Very much less is known about the effects of stopping smoking than about those of continuing to smoke. Consideration of the principal pathophysiological changes associated with the habit allows some conclusions to be drawn, however, from the results of studies which have specifically looked at the reversibility of changes induced by smoking.

While it is not known precisely which components of cigarette smoke are responsible for the long term cardiovascular hazard ${ }^{3}$ carbon monoxide and nicotine have important and immediate cardiovascular effects. Carbon monoxide reduces tissue oxygenation by two mechanisms: it reduces the amount of haemoglobin available for combination with oxygen (because of the formation of carboxyhaemoglobin), and it increases the affinity of haemoglobin for oxygen. ${ }^{4}$ It also probably has a weak negative inotropic action on the heart. ${ }^{5}$ The clinical importance of these effects is shown by the association between cigarettes with a high yield of carbon monoxide and an increase in symptoms of ischaemia in susceptible people. ${ }^{3}$ In addition, exercise tolerance is reduced in patients with ischaemic heart disease exposed to carbon monoxide. ${ }^{6}$ At blood concentrations commonly found in smokers nicotine causes an increase in heart rate and blood pressure. ${ }^{7}$ Hence nicotine increases demand of the myocardium for oxygen while carbon monoxide decreases the supply. A period of abstention from smoking for 12 to 24 hours preoperatively will allow the elimination of both carbon monoxide and nicotine and improve cardiovascular fitness. ${ }^{8.10}$ This is of particular clinical importance in patients with coronary artery disease.

(C) BRITISH MEDICAL JOURNAL 1985. All reproduction rights reserved.
A sixfold increase in postoperative respiratory morbidity in patients smoking more than 10 cigarettes a day was reported by Morton in $1944 .{ }^{11}$ Although the extent of the risk depends on the precise definition of postoperative respiratory morbidity numerous studies have confirmed Morton's original observation. ${ }^{12-14}$ Three mechanisms appear to be playing a part. These are small airways disease, hypersecretion of mucus, and impairment of tracheobronchial clearance. There is little or no improvement in tracheobronchial clearance one week after stopping smoking, ${ }^{15}$ and though the volume of sputum declines steadily over six weeks the clearance may remain abnormal for several months. ${ }^{16}$ Similarly, there seems to be no improvement in small airways disease one week after stopping smoking ${ }^{17}$ though some reversal of changes has been shown in most smokers after two months. ${ }^{18}{ }^{19} \mathrm{~A}$ minimum of six weeks' abstinence seems, therefore, to be needed before there is any beneficial influence on postoperative respiratory morbidity.

Smoking also affects several aspects of the immune response. These include a reduction in neutrophil chemotaxis, ${ }^{20}$ in immunoglobulin concentrations, and in natural killer cell activity. ${ }^{21}$ In addition, the pulmonary alveolar macrophage-one of the components of the local pulmonary defence mechanism - has been shown to be morphologically abnormal in smokers ${ }^{22}$ and to have a deranged metabolism..$^{23-25}$ One week's abstinence from smoking appears to improve the function of pulmonary alveolar macrophages to some extent, ${ }^{25}$ and after six weeks immunoregulatory $T$ cell activity has been reported to return to normal in heavy smokers. ${ }^{26}$ Again, therefore, a period of abstinence of six weeks appears to be associated with a return towards normal of some aspects of immune function.

Platelet aggregability is increased in smokers. ${ }^{27}$ What this means is unclear, however, because two separate studies (in different surgical populations) have reported a lower incidence of isotopically detected postoperative deep vein thrombosis in smokers compared with non-smokers. ${ }^{28}{ }^{29}$ Surgical patients who smoke tend to be younger and thinner than their nonsmoking counterparts, although this is unlikely to be the sole cause of the observed difference. ${ }^{29}{ }^{30}$ Furthermore, this paradoxical reduction in deep vein thrombosis in smokers has also been described after myocardial infarction. ${ }^{3132}$ In these circumstances it is difficult to separate the chronic effects of smoking itself from the possible consequences of a sudden imposed abstinence. Nevertheless, there is no evidence 
that smokers who stop smoking weeks or months before surgery are at an increased risk compared with non-smokers, and patients treated by the routine precautions against postoperative deep vein thrombosis (for example, subcutaneous heparin) should have a lower risk of thromboembolic phenomena.

Firm advice to stop smoking given in a hospital environment and repeated in follow up clinics is very successful in persuading people to stop smoking. ${ }^{33}$ Admission to hospital for surgery, with the general supportive atmosphere and emphasis on health and disease, provides a prime opportunity to persuade people to stop smoking. This opportunity should not be missed just because smokers appear to have a reduced incidence of deep vein thrombosis - a complication amenable to prevention by other means. Advice to patients to stop smoking as long as possible before surgery will undoubtedly benefit them-not only in the short term because of a reduction in perioperative morbidity-but also in the long term because of the risks of chronic pulmonary disease, carcinoma of the lung, and ischaemic heart disease.

In conclusion, roughly six weeks after stopping smoking patients may expect an improvement in pulmonary function, a reduction in postoperative respiratory morbidity, and a return towards normal immune responses. If, however, patients cannot be persuaded to stop smoking for this period (or permanently) considerable benefit will still accrue from the improvement in cardiovascular function brought about by even 12 to 24 hours of abstention from smoking - a factor of particular importance in patients with ischaemic heart disease.

R M JONES

Senior Lecturer in Anaesthetics,

United Medical and Dental Schools of Guy's and St Thomas's Hospitals,

London SE1 9RT

1 Stedman RL. The chemical composition of tobacco and tobacco smoke. Chemotherapy Review 1968;68:153-207.

2 Mitchell C, Garrahy P, Peake P. Postoperative respiratory morbidity: identification and risk factors. Aust NZ J Surg 1982;52:203-9.

3 Borland C, Chamberlain A, Higenbottam T, Shipley M, Rose G. Carbon monoxide yield of cigarettes and its relation to cardiorespiratory disease. $\mathrm{Br} \mathrm{Med} \mathcal{F}$ 1983;287:1583-6.

4 Roughton FJW, Darling RC. The effect of carbon monoxide on the oxyhemoglobin dissociation curve. Am f Physiol 1944;141:17-31.

5 Turino GM. Effect of carbon monoxide on the cardiorespiratory system. Circulation 1981;63:

6 Anderson EW, Alderman RJ, Strauch JM, Fortuin NJ, Knelson JH. Effect of low level CO exposure on onset and duration of angina pectoris. Ann Intern Med 1979;79:46-50. 7 Roth GM, Shick RM. The cardiovascular effects of smoking with special reference to

8 Hill D, Larcombe I, Refshauge JG. Smoking and impairment of performance. Med f Aust 1978;ii:60-3.

9 Rode A. Shephard RJ. The influence of cigarette smoking upon the oxygen cost of breathing in near-maximal exercise. Med Sci Sports Exerc 1971;3:51.

10 Seppänen. Physical work capacity in relation to carbon monoxide inhalation and tobacco smoking. Ann Clin Res 1977;9:269-74

11 Morton HJV. Tobacco smoking and pulmonary complications after operation. Lancet 1944; 368-70.

12 Wightman JAK. A prospective survey of the incidence of postoperative pulmonary complications. Br f Surg 1968;55:85-91.

13 Laszlo G, Archer GG, Darrell JH, Dawson JM, Fletcher CM. The diagnosis and prophylaxis of pulmonary complications of surgical operation. Br $\mathcal{F}$ Surg 1973;60:129-34

14 Chalon J, Tayyab MA, Ramanathan S. Cytology of respiratory epithelium as a predictor of respiratory complications after operation. Chest 1975;67:32-5.

15 Camner P, Philipson K, Arvidsson T. Withdrawal of cigarette smoking: a study on tracheobronchial clearance. Arch Environ Health 1973;26:90-2.

16 Goodman RM, Yergin BM, Landa JF, Golinvaux MH, Sackner MA. Relationship of smoking history and pulmonary function tests to tracheal mucous velocity in non smokers, young history and pulmonary function tests to tracheal mucous velocity in non smokers, young

17 Chodoff P, Margand PMS, Knowles CL. Short term abstinence from smoking: its place in preoperative preparation. Crit Care Med 1975;3:131-3.

18 Martin RR, Lindsay D, Despas P, et al. The early detection of airway obstruction. Am Rev Respir Dis 1975;111:119-25

19 Buist AS, Sexton GJ, Nagy JM, Ross BB. The effect of smoking cessation and modification on lung function. Am Rev Respir Dis 1976;114:115-22.

20 Corberand J, Nguyen F, Do AH, et al. Effect of tobacco smoking on the functions of polymorphonuclear leukocytes. Infect I mmun 1979;23:577-81.

21 Ferson M, Edwards A, Lind A, Milton GW, Hersey P. Low natural killer cell activity and immunoglobulin levels associated with smoking in human subjects. Int f Cancer 1979;23:603-9.

22 Martin RR. Altered morphology and increased acid hydrolase content of pulmonary macrophages from cigarette smokers. Am Rev Respir Dis 1973;107:596-601.

23 Hinman LM, Stevens CA, Matthay RA, Gee JBL. Elastase and lysozyme activities in human alveolar macrophages. Am Rev Respir Dis 1980;121:263-71.
24 Hoidal JR, Fox RB, LeMarbe PA, Perri R, Repine JE. Altered oxidative metabolic responses in vitro of alveoler macrophages from asymptomatic cigarette smokers. Am Rev Respir Dis 1981;123:85-9.

25 Rasp FL, Clawson CC, Hoidal JR, Repine JE. Reversible impairment of the adherence of alveolar macrophages from cigarette smokers. Am Rev Respir Dis 1978;118:979-86.

26 Miller LG, Goldstein G, Murphy M, Ginns LC. Reversible alterations in immunoregulatory T cells in smoking. Chest 1982;82:526-9.
ciller 2 , Goldstein G, Murphy M, Gings

27 Bierenbaum MD, Fleischman AI, Stier A, Somol H, Wabom PB. Effect of cigarette smoking upon in vivo platelet function in man. Thromb Res 1978;12:1051-7.

28 Clayton JK, Anderson JA, McNicol GP. Effect of cigarette smoking on subsequent postoperative thromboembolic disease in gynaecological patients. BrMed f 1978;ii:402.

29 Pollock AV, Evans M. Cigarette smoking and postoperative deep-vein thrombosis. Br Med 1978 ;i: 637.

30 Bucknall TE, Bowker T, Leaper DJ. Does increased movement protect smokers from postoperative deep vein thrombosis. Br Med f 1980;280:447.

31 Handley AJ, Teather D. Influence of smoking on deep vein thrombosis after myocardial

infarction. $B r M e d \mathcal{F} 1974 ; i i i: 230-1$.
32 Marks $\mathrm{P}$, Emerson PA. Increased incidence of deep vein thrombosis after myocardial infarction in non-smokers. Br Med f 1974;iii:232-4.

33 Burt A, Illingworth D, Shaw TRD, Thornley P, White P, Turner R. Stopping smoking after myocardial infarction. Lancet 1974; i:304-6.

\section{Initiatives in the preregistration year (general clinical training)}

When 12 months of postgraduate extra practical training was introduced in 1953 as a prerequisite for full registration the hope was that this step would allow the undergraduate course to become more truly educative. ${ }^{1}$ That hope seems to have failed, ${ }^{22}$ perhaps because of a combination of entrenched attitudes and the ever enlarging undergraduate curriculum, and despite the liberal style of the General Medical Council's recommendations on basic medical education.

Meanwhile, for the past 30 years the training experience of the preregistration year has remained more or less fixed in a pattern of six months' medicine and six months' surgery. This period of so called "general clinical training" to be regarded as a necessary and proper initiation rite for the young doctor. For the first time he comes face to face with life and death issues, for which he now shares some responsibility. He learns to work long hours. In 1980 the GMC's education committee extended its recommendations to cover this period with guidelines concerning patterns of experience and suitability of posts and hospitals and attempted to solve the problems being generated by ever increasing specialisation in medicine and surgery - for example, by providing for a period of training of up to four months spent in general practice within a health centre.

This potential development was an echo of similar and more elaborate proposals generated in the 1960 s by medical teachers ${ }^{4}$ and in the 1970 s by the Merrison committee. ${ }^{5}$ The latter proposals-for a two year period of graduate clinical training - had foundered at an early stage, largely because of some medical schools' protests that their five year long curricula (which would have been reduced to four years by the proposals) were solidly established and barely able to accommodate the content already demanded.

In practice, the GMC's encouragement to medical schools to look for new combinations of preregistration experience has led to just one experiment incorporating general practice and this within the University of London at St Mary's Hospital Medical School. A previous experimental post in Southampton in primary care had combined four months in the professorial medical unit and two months in the university health centre linked to a six month post in surgery; but this had faltered-apparently over the issue of prescribing. By contrast, the St Mary's experiment seems to have been highly successful (p 1811). 